\title{
Immunology of Cryptococcal Infections: Developing a Rational Approach to Patient Therapy
}

\author{
Waleed Elsegeiny ${ }^{1}$, Kieren A. Marr ${ }^{2}$ and Peter R. Williamson ${ }^{1 *}$ \\ ${ }^{1}$ Laboratory of Clinical Immunology and Microbiology (LCIM), National Institute of Allergy and Infectious Diseases (NIAID), \\ National Institutes of Health (NIH), Bethesda, MD, United States, ${ }^{2}$ Johns Hopkins University, Baltimore, MD, United States
}

\section{OPEN ACCESS}

Edited by:

Steven Templeton,

Indiana University School of Medicine - Terre Haute,

United States

Reviewed by:

Liise-anne Pirofski, Albert Einstein College of Medicine, United States

Simon Andrew Johnston,

University of Sheffield,

United Kingdom

Floyd Layton Wormley, University of Texas at San

Antonio, United States

*Correspondence:

Peter R. Williamson williamsonpr@mail.nih.gov

Specialty section: This article was submitted to Microbial Immunology, a section of the journal

Frontiers in Immunology

Received: 04 January 2018 Accepted: 16 March 2018

Published: 04 April 2018

Citation:

Elsegeiny W, Marr KA and Williamson PR (2018) Immunology

of Cryptococcal Infections:

Developing a Rational Approach to Patient Therapy.

Front. Immunol. 9:651. doi: 10.3389/fimmu.2018.00651
Cryptococcal meningoencephalitis is responsible for upwards of $15 \%$ of HIV-related deaths worldwide and is currently the most common cause of non-viral meningitis in the US, affecting both previously healthy and people with immune suppression caused by cancer chemotherapy, transplantation, and biologic therapies. Despite a continued 30-50\% attributable mortality, recommended therapeutic strategies have remained largely unchanged since the 1950s. Recent murine models and human studies examining the role of the immune system in both susceptibility to the infection as well as host damage have begun to influence patient care decisions. The Damage Framework Response, originally proposed in 1999, was recently used to discuss dichotomous etiologies of host damage in cryptococcal disease. These include patients suffering microbiological damage with low host immunity (especially those immunosuppressed with HIV) and those having low (live) microbiological burden but high immune-mediated damage (HIV-related immune reconstitution syndrome and non-HIV-related postinfectious inflammatory response syndrome). Cryptococcal disease in previously healthy hosts, albeit rare, has been known for a long time. Immunophenotyping and dendritic cell-T cell signaling studies on cerebral spinal fluid of these rare patients reveal immune capacity for recognition and T-cell activation pathways including increased levels of HLA-DR and CD56. However, despite effective T-cell signals, brain biopsy and autopsy specimens demonstrated an M2 alternative macrophage polarization and poor phagocytosis of fungal cells. These studies expand the paradigm for cryptococcal disease susceptibility to include a prominent role for immune-mediated damage and suggest a need for careful individual consideration of immune activation during therapy of cryptococcal disease in diverse hosts.

\section{Keywords: Cryptococcus, cryptococcal, meningoencephalitis, meningitis, neurology, infection, fungus}

\section{INTRODUCTION}

Cryptococcus is an opportunistic fungus, which most frequently presents as a pulmonary infection or meningoencephalitis. Cryptococcosis has a high impact on immunocompromised populations such as patients with HIV-AIDS and a wide array of non-HIV patients including those with hematopoietic malignancies, autoimmune diseases, or genetic immunodeficiency syndromes, as well as patients receiving immunosuppressive cancer-therapies, undergoing transplant conditioning, in combination with age-related immunosenescence (1-5). HIV-related cryptococcal meningitis (CM) is one 
the most common causes of adult meningitis with an estimated 223,100 cases and 181,100 deaths in 2014 , globally $(6,7)$. In countries with access to optimal medical care, non-HIV CM accounts for at least $25 \%$ of all CM-related hospitalization and deaths and is currently the leading cause of non-viral meningitis in the U.S. $(2,8-10)$. Interestingly, there are rare reports that as much as $30 \%$ of non-HIV patients with cryptococcal infection were previously healthy with no known underlying condition (11).

Cryptococcus is a basidiomycete yeast with over 30 known species; however, the majority of human infections are caused by either Cryptococcus neoformans and Cryptococcus gattii. C. neoformans is the main source of infections in CM patients with CD4+ T-cell deficiency while C. gattii is a predominant species in the previously healthy $(12,13)$. C. neoformans and C. gattii both can both be found in the vicinity of a variety of trees, and C. neoformans can also be found in soils and bird feces (14). Although the life-cycle of Cryptococcus is not dependent on an animal host, $C$. neoformans has the potential to infect a wide range of warm- and cold-blooded species (15). Cryptococci are considered sapronotic due to their ability to cause an opportunistic infection without coevolution of a host-parasite virulence (16) although molecular optimization of virulence has been noted in environmental strains after mammalian residence (17). Key to infecting such a wide-ranging host population is its adaptation to environmental conditions and defenses against innate plant defenses as well as phagocytic predators such as parasites and insects (18-21).

\section{CRYPTOCOCCAL INFECTION}

Cryptococcal infection is believed to be transmitted by inhalation of infective particles such as yeast cells and/or spores from an environmental source. It is believed that humans encounter the organism early in life, evident by the gradual increase of cryptococcal-specific antibodies in humans with age (22) and isolation of infective strain types from the country of origin in immigrant patients later presenting with HIV/AIDS-related CM (23). As most immunocompetent humans are asymptomatic and resolve the infection, there are limited observations as to the mechanism in which infection is cleared. Cryptococcus spp. has a unique repertoire of immune reactivity from other fungi because of distinguishing attributes such as a large polysaccharide capsule that limits exposure to immune dominant carbohydrate epitopes (20), immunomodulatory enzymes such as a phenol oxidizing and cytokine-inducing laccase (24), and a robust tolerance to low nutrient conditions such as within brain tissues $(25,26)$.

\section{INNATE RECOGNITION}

Although no single pattern recognition receptor (PRR) has been shown to be required for binding of Cryptococcus, it is hypothesized that alveolar macrophages recognize Cryptococcus and initialize the immune response through multiple receptors such as Dectin-1, Mincle, mannose receptor, CD14, and toll-like receptors (TLRs) (Figure 1.1) (27-30). The role of AMs and phagocytosis is believed to be critical during early infection, as observed in vivo imaging studies and animal models demonstrating enhanced susceptibility after AM depletion $(31,32)$. The complexity of how PRRs impact the immune response to cryptococcal infection is still being studied as there may be redundancy among them. For example, TLRs 2, 4, and 9 individually appear to play only a minor role, although the use of agonists in vitro enhances the proinflammatory responses by microglial cells to Cryptococcus (33). NOD-like receptor family pyrin domain containing 3 (NLRP3) is another cryptococcal recognizing PRR and has been shown in mice to be involved with leukocyte infiltration in the lung during infection (34). Interestingly, in vitro, NLRP3 activation appears to be inhibited by capsulated cryptococcal cells further suggesting that PRRs may have a more important role during early infection (35). Some PRRs have been linked to specific immune responses such as scavenger receptors B1 and SR-B3, which appear to be important for the induction of IL-1 $\beta$ (36). Macrophage receptor with collagenous structure (MARCO) is also a scavenger receptor which plays a role in cellular recruitment to the lung, cytokine production, and pathogen uptake by mononuclear phagocytes during early stages of cryptococcal infection (37). However, during the adaptive phase of infection, mice deficient in MARCO have improved fungal clearance which is marker by a type-I skewed immune response. Although MARCO plays an important role initially during infection, it is believed that Cryptococcus is capable of exploiting MARCO to polarize toward a non-protective immune response (38). There are other recognition receptors such as scavenger receptor A (SR-A) that are also associated with poorer response to Cryptococcus. SR-A-deficient mice show enhanced fungal clearance, which was correlated with decreased production of IL-4 and IL-13 (39). This may be linked to the unique cell wall composition of $C$. neoformans compared to other fungi, which contains high levels of acetylated chitin and deacetylated chitosan polymers (40). Furthermore, the binding of PRRs will become hindered as the infectious propagule starts forming the polysaccharide capsule, thus, it is believed that the successful phagocytosis of Cryptococcus also requires antibodyor complement-type opsonins $(41,42)$.

\section{INITIATION OF THE IMMUNE RESPONSE}

Although recognition and phagocytosis are important in induction of the immune response to Cryptococcus, the processes and pathways involved in breaking down and clearing pathogens and their antigens are also critical steps to mounting an optimal immune response. One clinical study observed that in vitro macrophage phagocytosis was directly correlated with clinical outcome (43). This suggests that other factors including phagocyte polarization and lysosomal activity may also need to be regulated for successful clearance.

Unlike other intracellular pathogens such as Mycobacterium tuberculosis, cryptococci do not interfere with phagosome formation or maturation; however, they are capable of surviving within vesicles or escaping by phagosome permeabilization or vesicular release (44-47). C. neoformans is thus capable of using macrophages as a host for immune evasion, and can escape through expulsion, lysis, or rupture due to excessive intracellular proliferation $(47,48)$. Alveolar macrophages are required; however, to recruit monocytes and dendritic cells (DCs) primarily through 


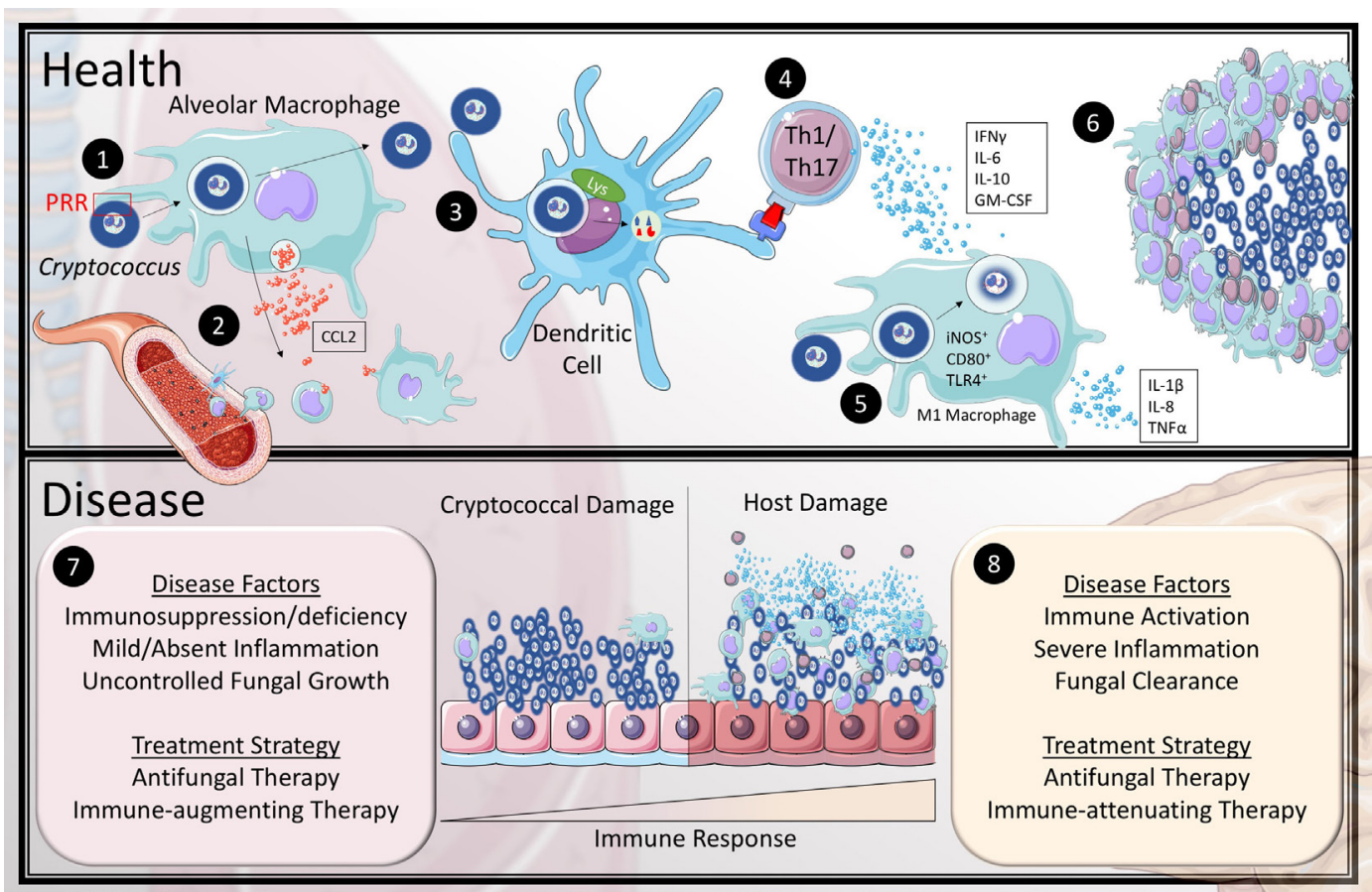

FIGURE 1 | Current model of the immune response to Cryptococcus in health and disease. In health (1) inhaled cryptococcal spores are recognized by alveolar macrophages through pattern recognition receptors (PRR). (2) This stimulates the macrophages to release CCL2 to recruit monocytes and dendritic cells (DCs) to the lung. (3) Recruited DCs are capable of breaking down cryptococcal lifeforms and present antigen to CD4+ T-cells. (4) Activated T helper 1 and Th17 T-cells secrete IFN $\gamma$, IL-6, IL-10, and granulocyte-macrophage colony stimulating factor (GM-CSF) to recruit and differentiate classical (M1) macrophages. (5) The exact mechanism of fungicidal activity by M1 macrophages against Cryptococcus is still unclear in humans; however, they are known to upregulate iNOS, CD80, and TLR4 as well as produce IL-1 $\beta$, IL-8, and TNF $\alpha$. (6) The cytokine and chemokine mileu organize the leukocytes to encapsulate and eliminate cryptococcal organisms within granulomas. The most common association with cryptococcal disease (7) is the absence or dysfunction of at least one aspect of the healthy immune response, which leads to uncontrolled fungal growth. (8) However, some patients develop a skewed hyper-immune response to the pathogen that causes inflammatory damage to the host tissue even with fungal clearance.

the production of macrophage chemotactic protein 1 (MCP1). In rats, MCP1 (also known as CCL2) and its receptor, CCR2, are essential for the recruitment of DCs, formation of granulomas, antigen presentation, and T-cell responses (Figure 1.2) $(49,50)$. Granulomas are a sign for control of infections and are composed of macrophages and giant multinucleated cells that contain cryptococcal cells, as well as CD4+ T-cells. These granulomas encompass the fungi and often resolve without additional medical assistance, but treatment with antifungal therapy or surgical removal of the lesions may expedite recovery. It has also been suggested that cryptococci may also be able to latently persist within granulomas and macrophages without degradation $(51,52)$. In patients with HIV-related pulmonary cryptococcosis, multinucleated giant cells are still present; however, the cryptococci are mainly extracellular and propagate within alveolar spaces (53). DCs are considered the primary antigen-presenting cell (APC) in the context of cryptococcal infection and have an advantage over macrophages in stimulating T-cell proliferation (54). Recruited DCs phagocytose cryptococcal bodies, which then are passaged through lysosomes to be degraded by both oxidative and non-oxidative mechanisms (Figure 1.3) (54, 55). For example, cathepsin-B has a non-enzymatic role to fracture the cell wall through osmotic lysis. Degraded components are then loaded onto major histocompatibility complex class II to initiate the adaptive immune response through CD4+ T-cell stimulation (Figure 1.4) (56). Eosinophils from a rat model of cryptococcosis have also been demonstrated to have the ability to phagocytose cryptococci and prime of CD4+ and CD8+ T-cells, in vitro (57) although their role in human infections is less clear. Their ability to function as APCs is associated with a decrease in nitric oxide and hydrogen peroxide production, followed by migration to the lymphatic system (58). However, their involvement in priming the adaptive immune response is associated with increased fungal burden and lung pathology by skewing immunity toward a typeII response $(59,60)$.

\section{THE ADAPTIVE IMMUNE RESPONSE}

Involvement of the adaptive immune compartment is critical for control of a cryptococcal infection; however, it may also have a detrimental affect depending on the type of response. In draining lymphoid tissues, APCs carrying cryptococcal antigens stimulate several types of lymphocytes including CD4+ T cells, CD8+ T cells, and natural killer T cells. Once activated, CD4+ T-cells can further differentiate into unique effector subsets with distinctive cytokine profiles including: T helper 1 (Th1), Th2, and 
Th17 cells. Cxcr5+ T follicular helper cells are also induced and primarily function to stimulate B cell maturation and antibody production, as well as activate inflammatory macrophages $(61,62)$. Th1 and Th17 cells are recognized by their production of IFN $\gamma$ and IL-17, respectively, and both help mediate the resolution of cryptococcal infection. On the other hand, Th2 cells, which are described as producers of IL-4, IL-5, and IL-13, are associated with more of a detrimental outcome such as increases in inflammation, worsened pathology, and increased risk of dissemination. In both humans and experimental murine models, deficiencies in type-II responses is linked with enhanced control of fungal burden and diminished eosinophilia, inflammation, airway damage, and dissemination $(63,64)$.

Interestingly, patients with HIV infection will gradually shift from a type-I to a type-II immune response profile, thus developing an increased vulnerability to cryptococcal infection (65). Profiling studies performed by Jarvis et al. on the cytokines and chemokines produced by stimulated peripheral blood mononuclear cells (PBMCs)-derived CD4+ T-cell as well as within cerebral spinal fluid (CSF) of patients with HIV-related $\mathrm{CM}$ have provided some immunological associations with survival $(66,67)$. Increased levels of IL-6, IL-8, IL-10, IL-17, IFN- $\gamma$, tumor necrosis factor (TNF), and CCL5 within the CSF correlated with high white cell counts, macrophage activation, reduced cryptococcal burden, and survival. A high proportion of IFN- $\gamma$ and TNF double producing PBMC-derived CD4+ T-cells was also associated with survival (68). This study corroborates the critical importance of maintaining a Th1/Th17 profile in both cryptococcal pulmonary infection and meningoencephalitis. Most CM studies have been performed in the context of HIV patients and C. neoformans; however, little is known about the immune profile in patients with non-HIV CM, particularly those with C. gattii infection.

\section{HUMORAL IMMUNITY TO Cryptococcus}

As previously mentioned, serum antibodies to Cryptococcus can be detected in early life. However, immunocompromised patients at risk for cryptococcal infection appear to have a defect in antibody responses, such as loss of glucuronoxylomannan (GXM), a capsular component reactive B-cells, as well as overall lower levels of peripheral blood memory IgM B cells $(69,70)$. Lower serum GXM-IgM antibody levels in both HIV+ as well as HIV- solid organ transplant patients is also associated with increased risk for development of cryptococcosis (71-73). Antibody-mediated phagocytosis may be important as the increase in capsular size has been shown to reduce complement-mediated phagocytosis (74). Furthermore, murine studies have demonstrated that the murine equivalent of IgM memory B cells, B-1 cells, can dampen fungal growth in vitro and in vivo, by inducing an earlier T-cell response, reducing dissemination, and enhancing macrophage phagocytosis (75-78). Additionally, adoptive transfer of IgM-sufficient wild-type mouse serum into Rag $1^{-/-}$mice demonstrated enhanced alveolar macrophage phagocytosis and a reduction in early dissemination compared to mice treated with IgM-deficient serum. The use of vaccines or antibody therapy to boost antifungal titers may thus provide protection against the development of cryptococcal disease (79-81).

\section{CRYPTOCOCCAL ELIMINATION}

The primary mechanism for pulmonary clearance is the formation and resolution of granulomas by macrophages. However, as previously mentioned, Cryptococcus is capable of surviving within resident alveolar macrophages, thus the macrophages required for clearance must be recruited and activated by CD4+ T-cell signals. Macrophages stimulated under Th1/Th17 or Th2 cytokine profiles become skewed toward either classical or alternative activation, respectively. Classically activated (M1) macrophages are primarily induced by IFN $\gamma$ and lipopolysaccharide, while type- 2 cytokines including IL- 4 and IL-13 induce alternatively activated (M2) macrophages and function through production of proline and polyamines (82). M1 and M2 macrophages in vitro have demonstrated different outcomes during intracellular parasitism by $C$. neoformans with type-1/type-17 conditions having enhanced fungicidal activity (Figure 1.5) (83). Furthermore, STAT1-deficient mice, which are deficient in M1 macrophages due to an inability to generate a strong Th1 profile, have a defect in anti-cryptococcal activity, which correlated with a decrease in NO production (84). In the previously mentioned cohort of nonHIV patients with CM, although there were intact Th1 signaling found in the CSF, autopsy results revealed an overrepresentation of M2 macrophages within central nervous system (CNS) tissues (85). Similarly, patients with granulocyte-macrophage colony stimulating factor (GM-CSF) autoantibodies are also at risk for CM and have an abundance of Th1 CD4+ T-cells, but also have a skewed M2 macrophage phenotype $(86,87)$. Activated M1 macrophages, with CD4+ T-cells, resolve the infection by entrapping and degrading the cryptococcal propagules through the formation of granulomas (Figure 1.6).

\section{BRAIN DISSEMINATION}

Uncontrolled cryptococcal infection will inevitably disseminate into the (CNS) leading to a life-threatening CM. There are currently three known methods of cryptococcal dissemination from the lung: (1) the disruption of blood vesicle integrity allowing passive transport into the blood stream, (2) intact endothelial cells may phagocytose the spores from the lung and expulse them into the blood stream, (3) macrophages may act as a Trojan Horse by transporting phagocytosed spores to the brain, and regurgitating the spores in a process known as vomocytosis. Both microbial and host factors have been identified to be involved in CNS invasion, including cryptococcal matrix metalloprotease, production of a urease enzyme (88), and increases in host brain inositol levels $(89,90)$.

\section{NON-HIV FACTORS OF SUSCEPTIBILITY}

Over 1,000 cases of CM are reported to occur in previously healthy people in the U.S. annually. Studying this population reveals unique vulnerability risks, including previously undiagnosed, rare immune-associated monogenic disorders or 
autoimmune diseases. Patients with autoantibodies to (GM-CSF) and interferon-gamma (IFN $\gamma$ ) were recently demonstrated to be susceptible to CM, emphasizing the T-cell/monocyte signaling pathway that is required for a successful immune response $(86,87,91)$. Interestingly, poor macrophage function was also demonstrated in a cohort of clinically refractory patients by a lack of iNOS expression and intact M2-related CD200R1 expression using immunohistochemistry of infected brain tissue (85). Further studies also demonstrated defective CSF activated macrophage TNF- $\alpha$ secretion, which may explain a lack of symptomatology and diagnostic delays in non-HIV related CM.

Historically, the most common syndrome associated with risk for CM is an idiopathic CD4 lymphopenia (ICL) that presents as a non-HIV-associated reduction or loss of CD4+ T-cells. The tremendous impact of CM on AIDS patients makes the importance of CD4 T-cells self-evident. However, ICL is a very heterogeneous disorder that has been implicated as a serious risk factor $(92,93)$ but many patients with ICL remain healthy. Recently, the concept of a "two hit" hypothesis was advanced by the finding of two ICL patients with CM who had additional autoantibodies to GMCSF or an otherwise benign, but functionally significant mutation in the IKBKG/NEMO gene, with reductions in NFKB T-cell signaling (94). Similarly, patients with monocytopenia, such as patients with a GATA2 deficiency, also have increased risk of developing CM (95-97). Monogenic disorders such as X-linked CD40L deficiency, chronic granulomatous disease, and Job syndrome are also associated with susceptibility to CM (98-100). T-cell suppressing biological therapy such as natalizumab or fingolimod is also a risk factor (101, 102).

\section{CRYPTOCOCCAL DISEASE: A REFLECTION OF HOST AND MICROBIOLOGICAL FACTORS}

Recently, there has been a greater appreciation that host damage can occur from either the toxic products of an overwhelming microbial infection or a pathological inflammatory response to the invading pathogen (Figure 1.7 and Figure 1.8), recently termed the damage-framework response (103). Cryptococcal disease is a classic example of this phenomenon, often occurring within the same patient during different stages of treatment $(104,105)$. For example, in the setting of HIV infection, clinical outcomes of primary therapy are related to clearance of the fungus $(106,107)$. However, a paradoxical immune reconstitution syndrome can also be seen in these same patients whereby, in the setting of microbiological control, reconstitution of the immune system after initiation of antiretroviral therapy (ART) results in a pathological central nervous system inflammatory response (7, 108-110). HIV-related CM further exemplifies differences in disease at these polar extremes of immune response-a recent study of 90 HIV patients with cryptococcal disease found that high levels of Th1-related cytokines INF-gamma and IL-6 were predictive of 2-week initial survival when pathogen load was high; whereas, the development of symptomatic cIRIS was associated with elevated activation with increased macrophage-related cytokines such as CCL2/MCP-1, CCL3/MIP1a, and GM-CSF (67).

Similar to HIV-related disease, in the initial stages of therapy of non-HIV patients, failure to achieve negative CSF fungal cultures at 2 weeks is associated with clinical failure (107). However, many more such patients develop refractory symptoms and/or clinical deterioration despite microbiological control, recently described in previously healthy patients as a postinfectious inflammatory response syndrome. Similar to that encountered with cIRIS in HIV, these patients have an activated CD4+ T-cell intrathecal compartment with minimal Th2 presence (85). Additionally, these patients have high levels of CD4+ T-cells in the CSF and within the intracranial Virchow-Robin channels, which displayed an activated phenotype, as measured by HLA-DR4 and CD56 positivity. Elevated Th1 CSF soluble cytokines such as INF-gamma and interferon-related CXCL10 confirmed the activated T-cell phenotype. In addition, a strong relationship between the T-cell activation marker, sCD27, and elevations of the axonal damage marker, neurofilament light chain protein, suggest that such inflammation is not a benign event, but pathological $(85,111)$. These observations were surprising as these conditions typically define a successful immune response, as understood from susceptibility studies in HIV-related disease. However, as described above, many of the previously healthy have defects in macrophage polarization, allowing disease susceptibility in the face of unrestrained T-cell-mediated host damage. Such findings also highlight the limitations of applying disease principles from one host to another without careful consideration.

\section{TREATMENT: TOWARD A MORE RATIONAL APPROACH TO ADJUNCTIVE THERAPY}

Treatment strategies for patients with CM should be developed to address damage caused by both the microbe and the pathological immune response; the disease framework is a useful guide (Figure 1.7 and Figure 1.8) (104). In the initial therapy of all patients, treatment with antifungals with a fungicidal agent such as amphotericin B is paramount and is typically continued with oral azole therapy to prevent relapse after initial negative CSF cultures (112-114). Those with low immunity (HIV prior to ART or patients with a skewed Th2 response to Cryptococcus), may benefit from potential immune adjuvants such as IFN $\gamma$ to accelerate microbiological control (115). In these cases, rates of clearance of CSF fungal cultures (early fungicidal activity) may be an important parameter $(67,106,107)$. However, in HIV patients who have developed cryptococcal immune reconstitution inflammatory syndrome (cIRIS) or in refractory non-HIV patients after microbiological control, attention needs to be drawn to the host damage side of the disease model-to minimize pathological effects of a dysregulated host response. In this setting, application of immune enhancers such as IFN $\gamma$ therapy (116) may lead to exacerbated inflammation and potentially cause irreparable neurological damage (85). In these patients, use of adjunctive immunosuppression including corticosteroids is increasingly reported to suppress pathological inflammatory responses and control cerebral 
edema, improving clinical response $(85,115-120)$. In the previously healthy CM patient, for example, successful application of adjunctive corticosteroids in refractory disease or after clinical deterioration requires a personalized strategy. When resources are available, CSF culture negativity and measures of CSF inflammation such as sCD27, CSF glucose, or choroid plexitis or ependymitis by MRI imaging can provide specific biomarkers of the relative contributions of microbe and host toward understanding an individual patient's condition $(85,120,121)$. Biomarkers may also be useful guides during corticosteroid tapers to prevent exacerbations.

However, applying this type of therapy successfully requires careful attention to concurrent microbial control, as corticosteroids suppress innate and acquired immune responses needed to maintain fungal clearance $(122,123)$. Indeed, corticosteroids can have a deleterious effect when applied without pre-established microbial control during primary therapy of HIV-related CM (Figure 1.7) (124). The complex heterogeneity of clinical pathologies that occur in various patients during HIV-related CM requires a thoughtful approach that considers the evolving damage caused by both the fungus and the immune response within defined sub-groups. In resource-limited regions, more studies are needed to understand the damage-response framework as it relates to CM in poorly controlled HIV infection, and to identify markers that can tailor resource appropriate therapies. Strategies to prevent CM in HIV (125) and to diagnose or empirically treat co-infections (126) may have tremendous impact on outcomes given the high prevalence of disease in some geographic regions (8). Risks for co-infections, such as tuberculosis and bacterial infections can be exacerbated without specific therapy in the presence of corticosteroids (127).

\section{REFERENCES}

1. Sloan DJ, Parris V. Cryptococcal meningitis: epidemiology and therapeutic options. Clin Epidemiol (2014) 6:169-82. doi:10.2147/CLEP.S38850

2. Pyrgos V, Seitz AE, Steiner CA, Prevots DR, Williamson PR. Epidemiology of cryptococcal meningitis in the US: 1997-2009. PLoS One (2013) 8(2):e56269. doi:10.1371/journal.pone.0056269

3. Durski KN, Kuntz KM, Yasukawa K, Virnig BA, Meya DB, Boulware DR. Cost-effective diagnostic checklists for meningitis in resource-limited settings. J Acquir Immune Defic Syndr (2013) 63(3):e101-8. doi:10.1097/ QAI.0b013e31828e1e56

4. Rajasingham R, Rhein J, Klammer K, Musubire A, Nabeta H, Akampurira A, et al. Epidemiology of meningitis in an HIV-infected Ugandan cohort. Am J Trop Med Hyg (2015) 92(2):274-9. doi:10.4269/ajtmh.14-0452

5. Jarvis JN, Meintjes G, Williams A, Brown Y, Crede T, Harrison TS. Adult meningitis in a setting of high HIV and TB prevalence: findings from 4961 suspected cases. BMC Infect Dis (2010) 10:67. doi:10.1186/14712334-10-67

6. Park BJ, Wannemuehler KA, Marston BJ, Govender N, Pappas PG, Chiller TM. Estimation of the current global burden of cryptococcal meningitis among persons living with HIV/AIDS. AIDS (2009) 23(4):525-30. doi:10.1097/ QAD.0b013e328322ffac

7. Williamson PR, Jarvis JN, Panackal AA, Fisher MC, Molloy SF, Loyse A, et al. Cryptococcal meningitis: epidemiology, immunology, diagnosis and therapy. Nat Rev Neurol (2017) 13(1):13-24. doi:10.1038/nrneurol.2016.167

8. Rajasingham R, Smith R, Park B, Jarvis J, Govender NP, Chiller T, et al. Global Burden of Disease of HIV-associated cryptococcal meningitis: an updated analysis. Lancet Infect Dis (2017) 17(8):873-81. doi:10.1016/ S1473-3099(17)30243-8

9. Pappas PG, Perfect JR, Cloud GA, Larsen RA, Pankey GA, Lancaster DJ, et al. Cryptococcosis in human immunodeficiency virus-negative patients
Other populations with risks for CM such as solid organ transplant recipients also require tailored approaches to prevention and treatment. In populations other than HIV, the feasibility of prevention strategies is limited due to a lower prevalence of disease. Much more attention is needed to better define appropriate therapeutic strategies. Since diagnosis typically occurs late, fungal burden can be high at diagnosis; at the same time, relatively intact and variable inflammatory responses can lead to exuberant inflammatory neurological damage similar to cIRIS (128). In these patients, attention needs to be focused on personalizing therapies according to which side of the host damage framework is most responsible for neurological pathology $(128,129)$.

\section{AUTHOR CONTRIBUTIONS}

The bulk of this manuscript was written by WE under the guidance of PW. PW and KM provided revisional comments and suggestions on both content and organization of this manuscript.

\section{ACKNOWLEDGMENTS}

The introduction diagram was designed using Servier Medical Art. Link to Creative Commons License: https://creativecommons.org/licenses/by/3.0/legalcode.

\section{FUNDING}

This research was supported by NIH/NIAID extramual grants AI109657 as well as funding from the NIAID intramural program, AI001123, and AI001124.

in the era of effective azole therapy. Clin Infect Dis (2001) 33(5):690-9. doi:10.1086/322597

10. Brizendine KD, Baddley JW, Pappas PG. Predictors of mortality and differences in clinical features among patients with cryptococcosis according to immune status. PLoS One (2013) 8(3):e60431. doi:10.1371/journal.pone. 0060431

11. Zhu LP, Wu JQ, Xu B, Ou XT, Zhang QQ, Weng XH. Cryptococcal meningitis in non-HIV-infected patients in a Chinese tertiary care hospital, 1997-2007. Med Mycol (2010) 48(4):570-9. doi:10.3109/13693780903437876

12. Farrer RA, Desjardins CA, Sakthikumar S, Gujja S, Saif S, Zeng Q, et al. Genome evolution and innovation across the four major lineages of Cryptococcus gattii. MBio (2015) 6(5):e868-815. doi:10.1128/mBio.00868-15

13. Hagen F, Khayhan K, Theelen B, Kolecka A, Polacheck I, Sionov E, et al. Recognition of seven species in the Cryptococcus gattii/Cryptococcus neoformans species complex. Fungal Genet Biol (2015) 78:16-48. doi:10.1016/j. fgb.2015.02.009

14. Reimão JQ, Drummond ED, Terceti Mde S, Lyon JP, Franco MC, de Siqueira AM. Isolation of Cryptococcus neoformans from hollows of living trees in the city of Alfenas, MG, Brazil. Mycoses (2007) 50(4):261-4. doi:10.1111/j.1439-0507.2007.01374.x

15. Casadevall A, Steenbergen JN, Nosanchuk JD. 'Ready made' virulence and 'dual use' virulence factors in pathogenic environmental fungi - the Cryptococcus neoformans paradigm. Curr Opin Microbiol (2003) 6(4):332-7. doi:10.1016/S1369-5274(03)00082-1

16. Kuris AM, Lafferty KD, Sokolow SH. Sapronosis: a distinctive type of infectious agent. Trends Parasitol (2014) 30(8):386-93. doi:10.1016/j. pt.2014.06.006

17. Hu G, Chen SH, Qiu J, Bennett JE, Myers TG, Williamson PR. Microevolution during serial mouse passage demonstrates FRE3 as a virulence adaptation gene in Cryptococcus neoformans. MBio (2014) 5(2):e941-914. doi:10.1128/ mBio.00941-14 
18. Warpeha KM, Park YD, Williamson PR. Susceptibility of intact germinating Arabidopsis thaliana to human fungal pathogens Cryptococcus neoformans and C. gattii. Appl Environ Microbiol (2013) 79(9):2979-88. doi:10.1128/ AEM.03697-12

19. McDonald T, Wiesner DL, Nielsen K. Cryptococcus. Curr Biol (2012) 22(14):R554-5. doi:10.1016/j.cub.2012.05.040

20. Zaragoza O, Rodrigues ML, De Jesus M, Frases S, Dadachova E, Casadevall A. The capsule of the fungal pathogen Cryptococcus neoformans. Adv Appl Microbiol (2009) 68:133-216. doi:10.1016/S0065-2164(09)01204-0

21. Steenbergen JN, Casadevall A. The origin and maintenance of virulence for the human pathogenic fungus Cryptococcus neoformans. Microbes Infect (2003) 5(7):667-75. doi:10.1016/S1286-4579(03)00092-3

22. Goldman DL, Khine H, Abadi J, Lindenberg DJ, Pirofski L, Niang R, et al. Serologic evidence for Cryptococcus neoformans infection in early childhood. Pediatrics (2001) 107(5):E66. doi:10.1542/peds.107.5.e66

23. Dromer F, Ronin O, Dupont B. Isolation of Cryptococcus neoformans var. gattii from an Asian patient in France: evidence for dormant infection in healthy subjects. J Med Vet Mycol (1992) 30(5):395-7. doi:10.1080/02681219280000511

24. Valdez PA, Vithayathil PJ, Janelsins BM, Shaffer AL, Williamson PR, Datta SK. Prostaglandin E2 suppresses antifungal immunity by inhibiting interferon regulatory factor 4 function and interleukin-17 expression in $\mathrm{T}$ cells. Immunity (2012) 36(4):668-79. doi:10.1016/j.immuni.2012.02.013

25. Waterman S, Hacham M, Hu G, Zhu X, Park Y, Shin S, et al. Role of a CUF1CTR4 copper regulatory axis in the virulence of Cryptococcus neoformans. J Clin Invest (2007) 117:794-802. doi:10.1172/JCI30006

26. Hu G, Hacham M, Waterman SR, Panepinto J, Shin S, Liu X, et al. PI3K signaling of autophagy is required for starvation tolerance and virulenceof Cryptococcus neoformans. J Clin Invest (2008) 118(3):1186-97. doi:10.1172/ JCI32053

27. Garcia-Rodas R, Zaragoza O. Catch me if you can: phagocytosis and killing avoidance by Cryptococcus neoformans. FEMS Immunol Med Microbiol (2012) 64(2):147-61. doi:10.1111/j.1574-695X.2011.00871.x

28. Levitz SM. Innate recognition of fungal cell walls. PLoS Pathog (2010) 6(4):e1000758. doi:10.1371/journal.ppat.1000758

29. Walsh NM, Wuthrich M, Wang H, Klein B, Hull CM. Characterization of C-type lectins reveals an unexpectedly limited interaction between Cryptococcus neoformans spores and Dectin-1. PLoS One (2017) 12(3): e0173866. doi:10.1371/journal.pone.0173866

30. Mansour MK, Reedy JL, Tam JM, Vyas JM. Macrophage Cryptococcus interactions: an update. Curr Fungal Infect Rep (2014) 8(1):109-15. doi:10.1007/ s12281-013-0165-7

31. Shao X, Mednick A, Alvarez M, van Rooijen N, Casadevall A, Goldman DL. An innate immune system cell is a major determinant of species-related susceptibility differences to fungal pneumonia. J Immunol (2005) 175(5): 3244-51. doi:10.4049/jimmunol.175.5.3244

32. Bojarczuk A, Miller KA, Hotham R, Lewis A, Ogryzko NV, Kamuyango AA, et al. Cryptococcus neoformans intracellular proliferation and capsule size determines early macrophage control of infection. Sci Rep (2016) 6:21489. doi:10.1038/srep21489

33. Redlich S, Ribes S, Schütze S, Eiffert H, Nau R. Toll-like receptor stimulation increases phagocytosis of Cryptococcus neoformans by microglial cells. J Neuroinflammation (2013) 10:71. doi:10.1186/1742-2094-10-71

34. Lei G, Chen M, Li H, Niu JL, Wu S, Mao L, et al. Biofilm from a clinical strain of Cryptococcus neoformans activates the NLRP3 inflammasome. Cell Res (2013) 23(7):965-8. doi:10.1038/cr.2013.49

35. Guo C, Chen M, Fa Z, Lu A, Fang W, Sun B, et al. Acapsular Cryptococcus neoformans activates the NLRP3 inflammasome. Microbes Infect (2014) 16(10):845-54. doi:10.1016/j.micinf.2014.08.013

36. Means TK, Mylonakis E, Tampakakis E, Colvin RA, Seung E, Puckett L, et al. Evolutionarily conserved recognition and innate immunity to fungal pathogens by the scavenger receptors SCARF1 and CD36. J Exp Med (2009) 206(3):637-53. doi:10.1084/jem.20082109

37. Xu J, Flaczyk A, Neal LM, Fa Z, Eastman AJ, Malachowski AN, et al. Scavenger receptor MARCO orchestrates early defenses and contributes to fungal containment during cryptococcal infection. J Immunol (2017) 198(9):3548-57. doi:10.4049/jimmunol.1700057

38. Xu J, Flaczyk A, Neal LM, Fa Z, Cheng D, Ivey M, et al. Exploitation of scavenger receptor, macrophage receptor with collagenous structure, by Cryptococcus neoformans promotes alternative activation of pulmonary lymph node $\mathrm{CD} 11 \mathrm{~b}(+)$ conventional dendritic cells and non-protective
Th2 bias. Front Immunol (2017) 8:1231. doi:10.3389/fimmu.2017. 01231

39. Qiu Y, Dayrit JK, Davis MJ, Carolan JF, Osterholzer JJ, Curtis JL, et al. Scavenger receptor a modulates the immune response to pulmonary Cryptococcus neoformans infection. J Immunol (2013) 191(1):238-48. doi:10.4049/jimmunol. 1203435

40. Wiesner DL, Specht CA, Lee CK, Smith KD, Mukaremera L, Lee ST, et al. Chitin recognition via chitotriosidase promotes pathologic type-2 helper T cell responses to cryptococcal infection. PLoS Pathog (2015) 11(3):e1004701. doi:10.1371/journal.ppat.1004701

41. Dan JM, Wang JP, Lee CK, Levitz SM. Cooperative stimulation of dendritic cells by Cryptococcus neoformans mannoproteins and $\mathrm{CpG}$ oligodeoxynucleotides. PLoS One (2008) 3(4):e2046. doi:10.1371/journal.pone. 0002046

42. Voelz K, May RC. Cryptococcal interactions with the host immune system. Eukaryot Cell (2010) 9(6):835-46. doi:10.1128/EC.00039-10

43. Sabiiti W, Robertson E, Beale MA, Johnston SA, Brouwer AE, Loyse A, et al. Efficient phagocytosis and laccase activity affect the outcome of HIVassociated cryptococcosis. J Clin Invest (2014) 124(5):2000-8. doi:10.1172/ JCI72950

44. Johnston SA, May RC. The human fungal pathogen Cryptococcus neoformans escapes macrophages by a phagosome emptying mechanism that is inhibited by Arp2/3 complex-mediated actin polymerisation. PLoS Pathog (2010) 6(8):e1001041. doi:10.1371/journal.ppat.1001041

45. Levitz SM, Nong SH, Seetoo KF, Harrison TS, Speizer RA, Simons ER. Cryptococcus neoformans resides in an acidic phagolysosome of human macrophages. Infect Immun (1999) 67(2):885-90.

46. Vandal OH, Nathan CF, Ehrt S. Acid resistance in mycobacterium tuberculosis. J Bacteriol (2009) 191(15):4714-21. doi:10.1128/JB.00305-09

47. Tucker SC, Casadevall A. Replication of Cryptococcus neoformans in macrophages is accompanied by phagosomal permeabilization and accumulation of vesicles containing polysaccharide in the cytoplasm. Proc Natl Acad Sci U S A (2002) 99(5):3165-70. doi:10.1073/pnas.052702799

48. Alvarez M, Casadevall A. Cell-to-cell spread and massive vacuole formation after Cryptococcus neoformans infection of murine macrophages. BMC Immunol (2007) 8:16. doi:10.1186/1471-2172-8-16

49. He W, Casadevall A, Lee SC, Goldman DL. Phagocytic activity and monocyte chemotactic protein expression by pulmonary macrophages in persistent pulmonary cryptococcosis. Infect Immun (2003) 71(2):930-6. doi:10.1128/ IAI.71.2.930-936.2003

50. Osterholzer JJ, Curtis JL, Polak T, Ames T, Chen GH, McDonald R, et al. CCR2 mediates conventional dendritic cell recruitment and the formation of bronchovascular mononuclear cell infiltrates in the lungs of mice infected with Cryptococcus neoformans. J Immunol (2008) 181(1):610-20. doi:10.4049/jimmunol.181.1.610

51. Garcia-Hermoso D, Janbon G, Dromer F. Epidemiological evidence for dormant Cryptococcus neoformans infection. J Clin Microbiol (1999) 37(10): 3204-9.

52. Goldman DL, Lee SC, Mednick AJ, Montella L, Casadevall A. Persistent Cryptococcus neoformans pulmonary infection in the rat is associated with intracellular parasitism, decreased inducible nitric oxide synthase expression, and altered antibody responsiveness to cryptococcal polysaccharide. Infect Immun (2000) 68(2):832-8. doi:10.1128/IAI.68.2.832-838.2000

53. Shibuya K, Hirata A, Omuta J, Sugamata M, Katori S, Saito N, et al. Granuloma and cryptococcosis. J Infect Chemother (2005) 11(3):115-22. doi:10.1007/ s10156-005-0387-X

54. Syme RM, Spurrell JC, Amankwah EK, Green FH, Mody CH. Primary dendritic cells phagocytose Cryptococcus neoformans via mannose receptors and Fcgamma receptor II for presentation to T lymphocytes. Infect Immun (2002) 70(11):5972-81. doi:10.1128/IAI.70.11.5972-5981.2002

55. Mansour MK, Latz E, Levitz SM. Cryptococcus neoformans glycoantigens are captured by multiple lectin receptors and presented by dendritic cells. J Immunol (2006) 176(5):3053-61. doi:10.4049/jimmunol.176.5.3053

56. Hole CR, Bui H, Wormley FL Jr, Wozniak KL. Mechanisms of dendritic cell lysosomal killing of Cryptococcus. Sci Rep (2012) 2:739. doi:10.1038/ srep00739

57. Garro AP, Chiapello LS, Baronetti JL, Masih DT. Rat eosinophils stimulate the expansion of Cryptococcus neoformans-specific CD4(+) and CD8(+) $\mathrm{T}$ cells with a T-helper 1 profile. Immunology (2011) 132(2):174-87. doi:10.1111/j.1365-2567.2010.03351.x 
58. Garro AP, Chiapello LS, Baronetti JL, Masih DT. Eosinophils elicit proliferation of naive and fungal-specific cells in vivo so enhancing a $\mathrm{T}$ helper type 1 cytokine profile in favour of a protective immune response against Cryptococcus neoformans infection. Immunology (2011) 134(2):198-213. doi:10.1111/j.1365-2567.2011.03479.x

59. Huffnagle GB, Boyd MB, Street NE, Lipscomb MF. IL-5 is required for eosinophil recruitment, crystal deposition, and mononuclear cell recruitment during a pulmonary Cryptococcus neoformans infection in genetically susceptible mice (C57BL/6). J Immunol (1998) 160(5):2393-400.

60. Holmer SM, Evans KS, Asfaw YG, Saini D, Schell WA, Ledford JG, et al. Impact of surfactant protein D, interleukin-5, and eosinophilia on cryptococcosis. Infect Immun (2014) 82(2):683-93. doi:10.1128/IAI.00855-13

61. Luckheeram RV,Zhou R, Verma AD, Xia B. CD4(+)T cells: differentiation and functions. Clin Dev Immunol (2012) 2012:925135. doi:10.1155/2012/925135

62. Gibson JF, Johnston SA. Immunity to Cryptococcus neoformans and C. gattii during cryptococcosis. Fungal Genet Biol (2015) 78:76-86. doi:10.1016/j. fgb.2014.11.006

63. Zhang Y, Wang F, Tompkins KC, McNamara A, Jain AV, Moore BB, et al. Robust Th1 and Th17 immunity supports pulmonary clearance but cannot prevent systemic dissemination of highly virulent Cryptococcus neoformans H99. Am J Pathol (2009) 175(6):2489-500. doi:10.2353/ajpath.2009.090530

64. Flaczyk A, Duerr CU, Shourian M, Lafferty EI, Fritz JH, Qureshi ST. IL-33 signaling regulates innate and adaptive immunity to Cryptococcus neoformans. J Immunol (2013) 191(5):2503-13. doi:10.4049/jimmunol.1300426

65. Altfeld M, Addo MM, Kreuzer KA, Rockstroh JK, Dumoulin FL, Schliefer K, et al. $\mathrm{T}(\mathrm{H}) 1$ to $\mathrm{T}(\mathrm{H}) 2$ shift of cytokines in peripheral blood of HIVinfected patients is detectable by reverse transcriptase polymerase chain reaction but not by enzyme-linked immunosorbent assay under nonstimulated conditions. J Acquir Immune Defic Syndr (2000) 23(4):287-94. doi:10.1097/00042560-200004010-00001

66. Jarvis JN, Casazza JP, Stone HH, Meintjes G, Lawn SD, Levitz SM, et al. The phenotype of the Cryptococcus-specific CD4 + memory T-cell response is associated with disease severity and outcome in HIV-associated cryptococcal meningitis. J Infect Dis (2013) 207(12):1817-28. doi:10.1093/infdis/jit099

67. Jarvis JN, Meintjes G, Bicanic T, Buffa V, Hogan L, Mo S, et al. Cerebrospinal fluid cytokine profiles predict risk of early mortality and immune reconstitution inflammatory syndrome in HIV-associated cryptococcal meningitis. PLoS Pathog (2015) 11(4):e1004754. doi:10.1371/journal.ppat.1004754

68. Scriven JE, Rhein J, Hullsiek KH, von Hohenberg M, Linder G, Rolfes MA, et al. Early ART after cryptococcal meningitis is associated with cerebrospinal fluid pleocytosis and macrophage activation in a multisite randomized trial. J Infect Dis (2015) 212(5):769-78. doi:10.1093/infdis/jiv067

69. Pirofski LA. Polysaccharides, mimotopes and vaccines for fungal and encapsulated pathogens. Trends Microbiol (2001) 9(9):445-51. doi:10.1016/ S0966-842X(01)02134-5

70. Subramaniam K, Metzger B, Hanau LH, Guh A, Rucker L, Badri S, et al. $\operatorname{IgM}(+)$ memory B cell expression predicts HIV-associated cryptococcosis status. J Infect Dis (2009) 200(2):244-51. doi:10.1086/599318

71. Deshaw M, Pirofski LA. Antibodies to the Cryptococcus neoformans capsular glucuronoxylomannan are ubiquitous in serum from HIV + and HIVindividuals. Clin Exp Immunol (1995) 99(3):425-32. doi:10.1111/j.13652249.1995.tb05568.x

72. Subramaniam K, French N, Pirofski LA. Cryptococcus neoformansreactive and total immunoglobulin profiles of human immunodeficiency virus-infected and uninfected Ugandans. Clin Diagn Lab Immunol (2005) 12(10):1168-76. doi:10.1128/CDLI.12.10.1168-1176.2005

73. Jalali Z, Ng L, Singh N, Pirofski LA. Antibody response to Cryptococcus neoformans capsular polysaccharide glucuronoxylomannan in patients after solid-organ transplantation. Clin Vaccine Immunol (2006) 13(7):740-6. doi:10.1128/CVI.00139-06

74. Zaragoza O, Taborda CP, Casadevall A. The efficacy of complementmediated phagocytosis of Cryptococcus neoformans is dependent on the location of $\mathrm{C} 3$ in the polysaccharide capsule and involves both direct and indirect C3-mediated interactions. Eur J Immunol (2003) 33(7):1957-67. doi:10.1002/eji.200323848

75. Fleuridor R, Zhong Z, Pirofski L. A human IgM monoclonal antibody prolongs survival of mice with lethal cryptococcosis. J Infect Dis (1998) 178(4):1213-6. doi:10.1086/515688

76. Subramaniam KS, Datta K, Quintero E, Manix C, Marks MS, Pirofski LA. The absence of serum IgM enhances the susceptibility of mice to pulmonary challenge with Cryptococcus neoformans. J Immunol (2010) 184(10):5755-67. doi:10.4049/jimmunol.0901638

77. Szymczak WA, Davis MJ, Lundy SK, Dufaud C, Olszewski M, Pirofski LA. X-linked immunodeficient mice exhibit enhanced susceptibility to Cryptococcus neoformans Infection. MBio (2013) 4(4):e265-213. doi:10.1128/ mBio.00265-13

78. Rohatgi S, Pirofski LA. Molecular characterization of the early B cell response to pulmonary Cryptococcus neoformans infection. J Immunol (2012) 189(12):5820-30. doi:10.4049/jimmunol.1201514

79. Chaturvedi AK, Hameed RS, Wozniak KL, Hole CR, Leopold Wager CM, Weintraub ST, et al. Vaccine-mediated immune responses to experimental pulmonary Cryptococcus gattii infection in mice. PLoS One (2014) 9(8):e104316. doi:10.1371/journal.pone.0104316

80. Mirza Z, Soto ER, Dikengil F, Levitz SM, Ostroff GR. Beta-glucan particles as vaccine adjuvant carriers. Methods Mol Biol (2017) 1625:143-57. doi:10.1007/978-1-4939-7104-6_11

81. Spero D, Levitz L, De Groot AS. Report from the field: overview of the sixth annual vaccine renaissance conference. Hum Vaccin Immunother (2013) 9(7):1555-7. doi:10.4161/hv.24833

82. Classen A, Lloberas J, Celada A. Macrophage activation: classical versus alternative. Methods Mol Biol (2009) 531:29-43. doi:10.1007/978-1-59745396-7_3

83. Voelz K, Lammas DA, May RC. Cytokine signaling regulates the outcome of intracellular macrophage parasitism by Cryptococcus neoformans. Infect Immun (2009) 77(8):3450-7. doi:10.1128/IAI.00297-09

84. Leopold Wager CM, Hole CR, Wozniak KL, Olszewski MA, Wormley FL Jr. STAT1 signaling is essential for protection against Cryptococcus neoformans infection in mice. J Immunol (2014) 193(8):4060-71. doi:10.4049/ jimmunol.1400318

85. Panackal AA, Wuest SC, Lin YC, Wu T, Zhang N, Kosa P, et al. Paradoxical immune responses in non-HIV cryptococcal meningitis. PLoS Pathog (2015) 11(5):e1004884. doi:10.1371/journal.ppat.1004884

86. Saijo T, Chen J, Chen SC, Rosen LB, Yi J, Sorrell TC, et al. Anti-granulocytemacrophage colony-stimulating factor autoantibodies are a risk factor for central nervous system infection by Cryptococcus gattii in otherwise immunocompetent patients. MBio (2014) 5(2):e912-4. doi:10.1128/mBio. 00912-14

87. Rosen LB, Freeman AF, Yang LM, Jutivorakool K, Olivier KN, Angkasekwinai N, et al. Anti-GM-CSF autoantibodies in patients with cryptococcal meningitis. J Immunol (2013) 190(8):3959-66. doi:10.4049/jimmunol.1202526

88. Cox G, Mukherjee J, Cole G, Casadeval 1A, Perfect J. Urease as a virulence factor in experimental cryptococcosis. Infect Immun (2000) 68:443-8. doi:10.1128/IAI.68.2.443-448.2000

89. Liu TB, Kim JC, Wang Y, Toffaletti DL, Eugenin E, Perfect JR, et al. Brain inositol is a novel stimulator for promoting Cryptococcus penetration of the blood-brain barrier. PLoS Pathog (2013) 9(4):e1003247. doi:10.1371/journal. ppat. 1003247

90. Santiago-Tirado FH, Onken MD, Cooper JA, Klein RS, Doering TL. Trojan horse transit contributes to blood-brain barrier crossing of a eukaryotic pathogen. MBio (2017) 8(1). doi:10.1128/mBio.02183-16

91. Browne SK, Burbelo PD, Chetchotisakd P, Suputtamongkol Y, Kiertiburanakul S, Shaw PA, et al. Adult-onset immunodeficiency in Thailand and Taiwan. N Engl J Med (2012) 367(8):725-34. doi:10.1056/NEJMoa1111160

92. Ahmad DS, Esmadi M, Steinmann WC. Idiopathic CD4 lymphocytopenia: spectrum of opportunistic infections, malignancies, and autoimmune diseases. Avicenna JMed (2013) 3(2):37-47. doi:10.4103/2231-0770. 114121

93. Gorska MM, Alam R. A mutation in the human Uncoordinated 119 gene impairs TCR signaling and is associated with CD4 lymphopenia. Blood (2012) 119(6):1399-406. doi:10.1182/blood-2011-04-350686

94. Panackal AA, Rosen LB, Uzel G, Davis MJ, Hu G, Adeyemo A, et al. Susceptibility to cryptococcal meningoencephalitis associated with idiopathic CD4(+) lymphopenia and secondary germline or acquired defects. Open Forum Infect Dis (2017) 4(2):ofx082. doi:10.1093/ofid/ofx082

95. Vinh DC, Patel SY, Uzel G, Anderson VL, Freeman AF, Olivier KN, et al. Autosomal dominant and sporadic monocytopenia with susceptibility to mycobacteria, fungi, papillomaviruses, and myelodysplasia. Blood (2010) 115(8):1519-29. doi:10.1182/blood-2009-03-208629

96. Hsu AP, Sampaio EP, Khan J, Calvo KR, Lemieux JE, Patel SY, et al. Mutations in GATA2 are associated with the autosomal dominant and sporadic 
monocytopenia and mycobacterial infection (MonoMAC) syndrome. Blood (2011) 118(10):2653-5. doi:10.1182/blood-2011-05-356352

97. Spinner MA, Sanchez LA, Hsu AP, Shaw PA, Zerbe CS, Calvo KR, et al. GATA2 deficiency: a protean disorder of hematopoiesis, lymphatics, and immunity. Blood (2014) 123(6):809-21. doi:10.1182/blood-2013-07-515528

98. Jacobs DH, Macher AM, Handler R, Bennett JE, Collen MJ, Gallin JI. Esophageal cryptococcosis in a patient with the hyperimmunoglobulin E-recurrent infection (Job's) syndrome. Gastroenterology (1984) 87(1):201-3.

99. Holland SM, DeLeo FR, Elloumi HZ, Hsu AP, Uzel G, Brodsky N, et al. STAT3 mutations in the hyper-IgE syndrome. N Engl J Med (2007) 357(16):1608-19. doi:10.1056/NEJMoa073687

100. Winkelstein JA, Marino MC, Ochs H, Fuleihan R, Scholl PR, Geha R, et al. The X-linked hyper-IgM syndrome: clinical and immunologic features of 79 patients. Medicine (Baltimore) (2003) 82(6):373-84. doi:10.1097/01. md.0000100046.06009.b0

101. Forrestel AK, Modi BG, Longworth S, Wilck MB, Micheletti RG. Primary cutaneous Cryptococcus in a patient with multiple sclerosis treated with fingolimod. JAMA Neurol (2016) 73(3):355-6. doi:10.1001/jamaneurol.2015.4259

102. Valenzuela RM, Pula JH, Garwacki D, Cotter J, Kattah JC. Cryptococcal meningitis in a multiple sclerosis patient taking natalizumab. J Neurol Sci (2014) 340(1-2):109-11. doi:10.1016/j.jns.2014.03.007

103. Casadevall A, Pirofski LA. Host-pathogen interactions: redefining the basic concepts of virulence and pathogenicity. Infect Immun (1999) 67(8):3703-13.

104. Pirofski LA, Casadevall A. Immune-mediated damage completes the parabola: Cryptococcus neoformans pathogenesis can reflect the outcome of a weak or strong immune response. MBio (2017) 8(6):e02063-17. doi:10.1128/ mBio.02063-17

105. Panackal AA, Williamson KC, van de Beek D, Boulware DR, Williamson PR. Fighting the monster: applying the host damage framework to human central nervous system infections. MBio (2016) 7(1):e1906-15. doi:10.1128/ mBio.01906-15

106. Bicanic T, Meintjes G, Wood R, Hayes M, Rebe K, Bekker L, et al. Fungal burden, early fungicidal activity, and outcome in cryptococcal meningitis in antiretroviral-naive or antiretroviral-experienced patients treated with amphotericin B or fluconazole. Clin Infect Dis (2007) 45:76-80. doi:10.1086/ 518607

107. Montezuma-Rusca JM, Powers JH, Follmann D, Wang J, Sullivan B, Williamson PR. Early fungicidal activity as a candidate surrogate endpoint for all-cause mortality in cryptococcal meningitis: a systematic review of the evidence. PLoS One (2016) 11(8):e0159727. doi:10.1371/journal. pone. 0159727

108. Jenny-Avital E, Abadi M. Immune reconstitution cryptococcosis after initiation of successful highly active antiretroviral therapy. Clin Infect Dis (2002) 35:e128-33. doi:10.1086/344467

109. Longley N, Harrison TS, Jarvis JN. Cryptococcal immune reconstitution inflammatory syndrome. Curr Opin Infect Dis (2013) 26(1):26-34. doi:10.1097/ QCO.0b013e32835c21d1

110. Bahr NC, Wallace J, Frosch AE, Boulware DR. Unmasking cryptococcal meningitis immune reconstitution inflammatory syndrome due to granulocyte colony-stimulating factor use in a patient with a poorly differentiated germ cell neoplasm. Case Rep Oncol (2014) 7(1):1-5. doi:10.1159/000357666

111. Bacioglu M, Maia LF, Preische O, Schelle J, Apel A, Kaeser SA, et al. Neurofilament light chain in blood and CSF as marker of disease progression in mouse models and in neurodegenerative diseases. Neuron (2016) 91(1):56-66. doi:10.1016/j.neuron.2016.05.018

112. Dismukes WE, Cloud G, Gallis HA, Kerkering TM, Medoff G, Craven PC, et al. Treatment of cryptococcal meningitis with combination amphotericin B and flucytosine for four as compared with six weeks. N Engl J Med (1987) 317(6):334-41. doi:10.1056/NEJM198708063170602

113. Sarosi GA, Parker JD, Doto IL, Tosh FE. Amphotericin B in cryptococcal meningitis. Long-term results of treatment. Ann Intern Med (1969) 71(6):1079-87. doi:10.7326/0003-4819-71-6-1079

114. Diamond RD, Bennett JE. Prognostic factors in cryptococcal meningitis. A study in 111 cases. Ann Intern Med (1974) 80(2):176-81. doi:10.7326/00034819-80-2-176

115. Jarvis JN, Meintjes G, Rebe K, Williams GN, Bicanic T, Williams A, et al. Adjunctive interferon-gamma immunotherapy for the treatment of
HIV-associated cryptococcal meningitis: a randomized controlled trial. AIDS (2012) 26(9):1105-13. doi:10.1097/QAD.0b013e3283536a93

116. Perfect JR, Dismukes WE, Dromer F, Goldman DL, Graybill JR, Hamill RJ, et al. Clinical practice guidelines for the management of cryptococcal disease: 2010 update by the infectious diseases society of america. Clin Infect Dis (2010) 50(3):291-322. doi:10.1086/649858

117. Pappas PG, Bustamante B, Ticona E, Hamill RJ, Johnson PC, Reboli A, et al. Recombinant interferon-gamma $1 \mathrm{~b}$ as adjunctive therapy for AIDSrelated acute cryptococcal meningitis. J Infect Dis (2004) 189(12):2185-91. doi:10.1086/420829

118. Chen SC, Korman TM, Slavin MA, Marriott D, Byth K, Bak N, et al. Antifungal therapy and management of complications of cryptococcosis due to Cryptococcus gattii. Clin Infect Dis (2013) 57(4):543-51. doi:10.1093/cid/ cit341

119. Mehta GU, Panackal AA, Murayi R, Bennett JE, Williamson PR, Chittiboina P. Corticosteroids for shunted previously healthy patients with non-HIV cryptococcal meningoencephalitis. J Neurol Neurosurg Psychiatry (2017). doi:10.1136/jnnp-2017-315830

120. Panackal AA, Komori M, Kosa P, Khan O, Hammoud DA, Rosen LB, et al. Spinal arachnoiditis as a complication of cryptococcal meningoencephalitis in non-HIV previously healthy adults. Clin Infect Dis (2017) 64(3):275-83. doi:10.1093/cid/ciw739

121. Hammoud DA, Mahdi E, Panackal AA, Wakim P, Sheikh V, Sereti I, et al. Choroid plexitis and ependymitis by magnetic resonance imaging are biomarkers of neuronal damage and inflammation in HIV-negative cryptococcal meningoencephalitis. Sci Rep (2017) 7(1):9184. doi:10.1038/ s41598-017-09694-0

122. Collins JV, Tong D, Bucknall RG, Warin AP. Cryptococcal meningitis as a complication of systemic lupus erythematosus treated with systemic corticosteroids. Postgrad Med J (1972) 48(555):52-5. doi:10.1136/pgmj.48.555.52

123. Rinehart JJ, Balcerzak SP, Sagone AL, LoBuglio AF. Effects of corticosteroids on human monocyte function. J Clin Invest (1974) 54(6):1337-43. doi:10.1172/JCI107880

124. Beardsley J, Wolbers M, Kamali A, Cuc NT, Chierakul W, Chan AK, et al. Adjunctive Corticosteroids in HIV-associated cryptococcal meningitis: a randomised controlled trial in African and Southeast Asian Adults. 55th Interscience Conference on Antimicrobial Agents and Chemotherapy. San Diego, CA (2015).

125. Meya DB, Manabe YC, Castelnuovo B, Cook BA, Elbireer AM, Kambugu A, et al. Cost-effectiveness of serum cryptococcal antigen screening to prevent deaths among HIV-infected persons with a CD4 + cell count $<$ or $=100$ cells/ microL who start HIV therapy in resource-limited settings. Clin Infect Dis (2010) 51(4):448-55. doi:10.1086/655143

126. Hakim J, Musiime V, Szubert AJ, Mallewa J, Siika A, Agutu C, et al. Enhanced prophylaxis plus antiretroviral therapy for advanced HIV infection in Africa. N Engl J Med (2017) 377(3):233-45. doi:10.1056/NEJMoa1615822

127. Beale MA, Sabiiti W, Robertson EJ, Fuentes-Cabrejo KM, O’Hanlon SJ, Jarvis JN, et al. Genotypic diversity is associated with clinical outcome and phenotype in cryptococcal meningitis across Southern Africa. PLoS Negl Trop Dis (2015) 9(6):e0003847. doi:10.1371/journal.pntd.0003847

128. Sun HY, Singh N. Opportunistic infection-associated immune reconstitution syndrome in transplant recipients. Clin Infect Dis (2011) 53(2):168-76. doi:10.1093/cid/cir276

129. Sun HY, Wagener MM, Singh N. Cryptococcosis in solid-organ, hematopoietic stem cell, and tissue transplant recipients: evidence-based evolving trends. Clin Infect Dis (2009) 48(11):1566-76. doi:10.1086/598936

Conflict of Interest Statement: The authors declare that the research was conducted in the absence of any commercial or financial relationships that could be construed as a potential conflict of interest.

Copyright (๑) 2018 Elsegeiny, Marr and Williamson. This is an open-access article distributed under the terms of the Creative Commons Attribution License (CC BY). The use, distribution or reproduction in other forums is permitted, provided the original author(s) and the copyright owner are credited and that the original publication in this journal is cited, in accordance with accepted academic practice. No use, distribution or reproduction is permitted which does not comply with these terms. 